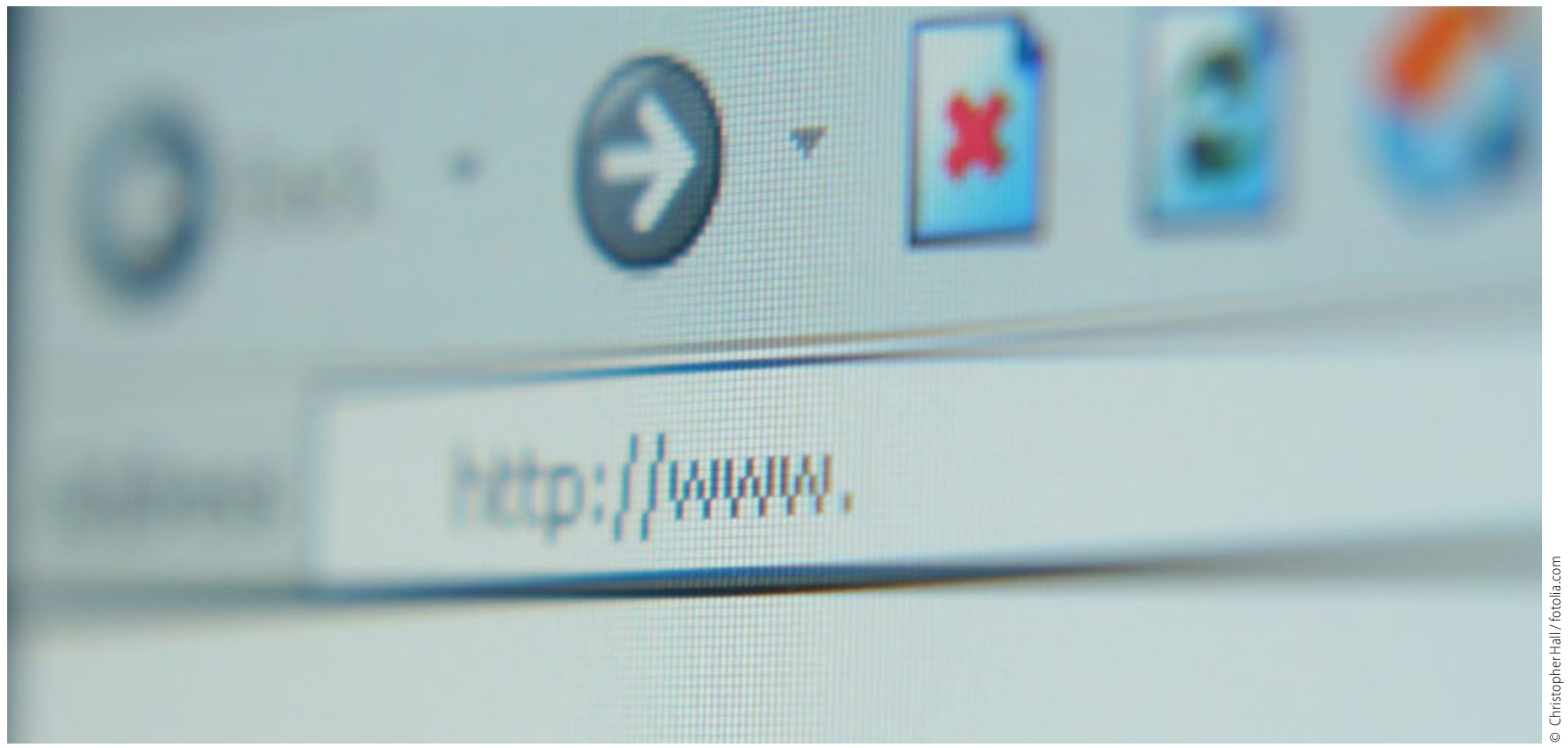

Urteil zu exzessiver Privatnutzung des Internets

\title{
Arbeitgeber dürfen Browserverlauf kontrollieren
}

\begin{abstract}
Wenn ein Arbeitnehmer das dienstliche Internet mehr nutzt als vereinbart, muss er mit Kontrollen und Konsequenzen rechnen. Darüber hat das Landesarbeitsgericht Berlin-Brandenburg in einer Entscheidung vom 14.01.2016 (5 Sa 657/15) entschieden. Abzuwägen war besonders das Persönlichkeitsrecht des Arbeitnehmers mit den Interessen des Arbeitgebers an der Aufdeckung und Sanktionierung von Pflichtverstößen.
\end{abstract}

In dem konkreten Fall nutzte ein Arbeitnehmer exzessiv den geschäftlichen Internetanschluss für private Zwecke - und zwar in 30 Arbeitstagen 40 Stunden. Daraufhin wurde ihm außerordentlich gekündigt. Dem Arbeitnehmer war eine private Nutzung des Internets allenfalls in Ausnahmefällen während der Arbeitspausen gestattet.

\section{Kein Beweisverwertungsverbot}

Das LAG kam in dem Fall zu dem Ergebnis, dass der Arbeitgeber im Kündigungsschutzprozess die Einträge der aufgerufenen Internetseiten in der Chronik des Internetbrowsers zum Beweis einer exzessiven Internetnutzung verwerten dürfe, ohne den Arbeitnehmer hinzuzuziehen. Obwohl es sich dabei um personenbezogene Daten handele und auch wenn eine wirksame Einwilligung in die Kontrolle dieser Daten nicht vorliege, bestehe kein Beweisverwertungsverbot, weil das Bundesdatenschutzgesetz auch ohne Einwilligung des Arbeitnehmers die Speicherung und Auswertung der Verlaufsdaten in der Chronik eines Internetbrowsers zu Zwecken der Missbrauchskontrolle erlaube. Unabhängig davon bestehe jedenfalls dann kein Beweisverwertungsverbot, wenn dem Arbeitgeber ein mit anderen Mitteln zu führender konkreter Nachweis des Umfangs des Missbrauchs nicht zur Verfügung steht.

Das Landesarbeitsgericht hat die Revision an das Bundesarbeitsgericht zugelassen, womit man gespannt sein kann, ob diese Entscheidung Bestand hat. Für Arbeitgeber empfiehlt es sich, die Frage der Internetnutzung explizit im Arbeitsvertrag zu regeln. Sinn macht es hier, eine private Internetnutzung generell auszuschließen, nicht zuletzt auch vor dem Hintergrund der Gefahren durch Computerviren.

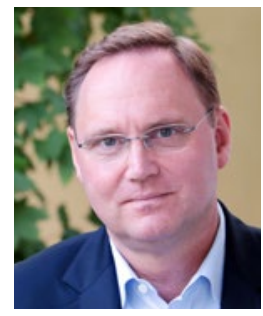

RA Michael Lennartz

www.lennmed.de 